\title{
Efficient Sex Pheromone Trapping: Catching The Sweetpotato Weevil, Cylas formicarius
}

\section{Authors: G. V. P. Reddy, Nirupa Gadi, \& Anthony J. Taianao}

This is a postprint of an article that originally appeared in Journal of Chemical Ecology in July 2012. The final publication is available at Springer via http://dx.doi.org/10.1007/s10886-012-0160-4

Reddy, G.V.P., N. Gadi, and A.J. Taianao. 2012. Efficient sex pheromone trapping: catching the sweetpotato weevil Cylas formicarius. Journal of Chemical Ecology 38: 846-853. doi: 10.1007/s10886-012-0160-4 


\title{
Efficient Sex Pheromone Trapping: Catching The Sweetpotato Weevil, Cylas formicarius
}

\author{
G. V. P. Reddy • Nirupa Gadi • Anthony J. Taianao
}

Received: 14 December 2011 /Revised: 17 March 2012 / Accepted: 24 May 2012 /Published online: 11 July 2012

(C) Springer Science+Business Media, LLC 2012

\begin{abstract}
The sweetpotato weevil, Cylas formicarius (Fabricius) (Coleoptera: Brentidae), is the most serious pest of sweetpotato around the world, damaging sweetpotatoes in the field and in storage, as well as being a quarantine pest. Because the larval period is spent within vines or tubers, and the adults are nocturnal, chemical control frequently is not effective. In addition, there are few natural enemies, and pheromone-based trapping does not appear to reduce the damage level. In the present study, we evaluated a number of parameters that affect pheromone-based trap catch, including trap design, trap size, trap color, and height at which the traps are placed. Pherocon unitraps caught higher numbers than ground, funnel water, or delta traps. Medium-sized traps $(13 \times 17.5 \mathrm{~cm})$ were more effective than larger or smaller traps. In a color-choice test, $C$. formicarius preferred red over gray, brown, blue, white, yellow, black, or red traps; light red was more attractive than other shades of red. Maximum catches were obtained when the traps were set $50 \mathrm{~cm}$ above the crop canopy. Light-red unitraps with pheromone lures caught more adults than identical traps without lures, suggesting that C. formicarius is influenced by both visual and olfactory cues. Pheromone-baited light-red unitraps, $13 \times 17.5 \mathrm{~cm}$, installed $50 \mathrm{~cm}$ above the crop canopy, were the most effective at catching $C$. formicarius adults, and they appear to have the greatest potential for use in trap-and-kill strategies and eradication programs.
\end{abstract}

\section{G. V. P. Reddy $(\bowtie)$}

Western Triangle Ag Research Center, Montana State University, 9546 Old Shelby Rd,

Conrad, MT 59425, USA

e-mail: reddy@montana.edu

N. Gadi $\cdot$ A. J. Taianao

Western Pacific Tropical Research Center,

College of Natural and Applied Sciences, University of Guam,

Mangilao, Guam 96923, USA
Keywords Sex pheromone $\cdot$ Cylas formicarius $\cdot$ Traps characteristics $\cdot$ Trap design $\cdot$ Size $\cdot$ Color $\cdot$ Height . Coleoptera $\cdot$ Curculionidae $\cdot$ Brentidae

\section{Introduction}

The sweetpotato, Ipomoea batatas (L.) Lam. (Convolvulaceae), is one of the most important food crops in the world, particularly in emerging countries, where it is a food staple (Woolfe, 1992). Its production is severely affected by several insect pests (Chalfant et al., 1990), of which the sweetpotato weevil, Cylas formicarius (Fabricius) (Coleoptera: Brentidae), is the most serious worldwide (Austin et al., 1991). Feeding by this weevil elicits terpenoid production in sweet-potato storage tubers that results in damaged, unpalatable tubers (Uritani et al., 1975). Sutherland (1986) reported that yield losses due to C. formicarius damage range from 5 to $80 \%$. The weevil completes its life cycle within either the tubers or vines of the sweetpotato plant, but prefers tubers (Strong, 1983).

Because of the high incidence of $C$. formicarius on sweetpotatoes, some growers in the Mariana Islands of the South Pacific have become frustrated and given up cultivation entirely. Even small weevil populations can cause severe damage to tubers, especially because the pest is present throughout the year in warm conditions (Sutherland, 1986), with weevil incidence extremely high during the hot and humid season (Chalfant et al., 1990). In Micronesia, $C$. formicarius infestations are particularly severe. Our preliminary trapping studies conducted over a year indicate that populations are high throughout Guam. Guam and other Micronesian Islands are in the midst of a decline in sweetpotato production because of the impact of this weevil (Hwang, 2001). Anecdotally, according to local growers and authorities, thousands of sweetpotato plants in this 
region have been damaged by $C$. formicarius. Although some control methods exist, chemical application is both undesirable and expensive. Without effective control, weevil populations are likely to cause very high or complete loss of sweetpotato production in Guam and other Micronesian Islands.

Chemical control in the field reduces $C$. formicarius numbers, but with varying degrees of success (Talekar, 1983). The protected position of the larvae, developing within the vines and tubers, limits the effectiveness of chemical treatments (Sutherland, 1986). Chalfant et al. (1990) reported a range of hormones and insect growth regulators that have varying effects on $C$. formicarius, but further research on these techniques is required. Cultural controls, such as the use of $C$. formicarius - resistant cultivars of I. batatas, non-infested planting material, and crop rotation, along with various management regimes, also reduce pest infestations (Jansson et al., 1987).

The cryptic feeding habits of the larvae, and the nocturnal activity of the adults make detection and control of infestations difficult. Resistant varieties of sweetpotato have not yet been used by growers (Downham et al., 2001). Sexpheromone lures are effective in detecting infestations at low population levels, and for use as a component of control and management (Reddy and Guerrero, 2004, 2010). Coffelt et al. (1978) isolated and bioassayed the female-produced sex pheromone of $C$. formicarius. Heath et al. (1986) purified, identified, and synthesized the active component as (Z)-3-dodecen-1-ol (E)-2-butenoate, and field studies on the development of traps and lures for this species were carried out (Jansson et al., 1992, 1993). The electrophysiological and behavioral responses of $C$. formicarius showed the synthetic compound to be highly attractive in the field, highlighting its potential for use in pest control (Sureda et al., 2006). Mass trapping has suppressed populations of $C$. formicarius males in several countries (e.g., Yasuda, 1995), although there has not always been concomitant reductions in the infestation rates or increases in sweetpotato yields (see, e.g., Braun and Van De Fliert, 1999). However, use of the pheromone in a pest-management strategy in India has resulted in a considerable reduction of damage, leading to a $53 \%$ increase in production of marketable tubers (Pillai et al., 1993). Trapping also has reduced the number of roots damaged by $C$. formicarius in the Caribbean (Alcázar et al., 1997, Jackson and Bohac, 2006). It has been estimated that the use of pheromone-baited traps as part of an integrated pest-management program for $C$. formicarius could reduce one to three insecticide applications per season (Hwang, 2000).

Characteristics such as trap design, size, color, and height are known to influence the efficacy of pheromone-baited traps for other species of tropical weevils (Reddy et al., 2011). Therefore, we undertook field studies to evaluate the effects of trap characteristics that may increase the effectiveness of trapping programs for $C$. formicarius.

\section{Methods and Materials}

Experimental Field Sites Experiments were carried out on the island of Guam (USA) at 4 locations: Latte Heights $\left(13^{\circ} 26^{\prime} \mathrm{N}, 144^{\circ} 48^{\prime} \mathrm{E}, 79.9 \mathrm{~m}\right.$ above sea level), Dededo $\left(13^{\circ} 30^{\prime} \mathrm{N}, 144^{\circ} 51^{\prime} \mathrm{E}, 96.9 \mathrm{~m}\right)$, Mangilao $\left(13.43^{\circ} \mathrm{N}, 144.80^{\circ} \mathrm{E}\right.$, $54.3 \mathrm{~m}$ ), and the University of Guam's Agricultural Experiment Station (AES) in Yigo $\left(13.31^{\circ} \mathrm{N}, 144.52^{\circ} \mathrm{E}^{\prime}, 138 \mathrm{~m}\right)$. The prevailing temperature, relative humidity, and wind velocity were recorded during the experimental period. Nearby sweetpotato fields were covered densely with various invasive plant species such as Chromolaena odorata (L.) R.M. King \& H. Rob. (Asteraceae), Panicum maximum Jacq (Poaceae), Lantana camara (L.) (Verbenaceae), and Bidens alba (L.) (Asteraceae). In addition, the morning glory, Ipomoea triloba (L.), known to be a major alternative host for C. formicarius (Austin et al., 1991), was present at most of the study locations.

Trap Design In the first experiment, four different types of traps, ground, funnel water, Pherocon unitrap, and Pherocon delta were evaluated. The ground trap (Fig. 1a) was constructed in our laboratory from a $120 \times 60 \times 0.5 \mathrm{~cm}$ piece of white corrugated plastic board, with a $50 \times 8 \mathrm{~cm}$ slit baffle fitted at the top to prevent weevils from escaping (Reddy et al., 2005). Traps were sealed at all corners and along edges

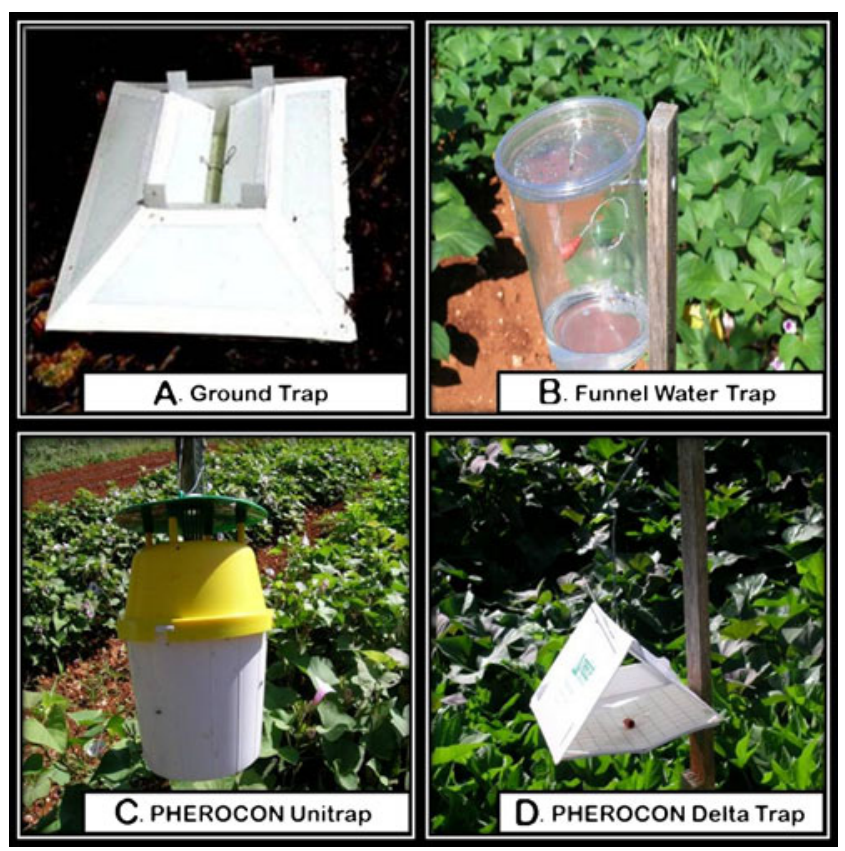

Fig. 1 The four trap designs used 
with marine adhesive sealant, and water mixed with a liquid dishwashing detergent (1-3\%) was placed in the bottom container to retain adults. The lower outer edges of the ground traps were covered with earth to prevent weevils from crawling under them.

Funnel water traps (Fig. 1b) were commercially available from Trécé Incorporated (Adair, OK, USA). Each trap consisted of a transparent, covered plastic cup (1 L capacity) with two $3 \mathrm{~cm}$ circular holes in the sides, near the top; $250 \mathrm{ml}$ of water mixed with detergent (1-3\%) were placed in the bottom of the cup. The trap was fitted with a wire linkage allowing it to be hung from a wooden post in the field.

The Pherocon unitraps (also called bucket traps), $20.5 \mathrm{~cm}$ high $\times 13 \mathrm{~cm}$ diam. also were obtained from Trécé Incorporated (Fig. 1c). Each unitrap consisted of a funnel-shaped white plastic receptacle, with a yellow plastic lid and holder for lures, mounted over a bucket for retaining captured insects. Because the unitrap incorporated a funnel ending in a pot from which insects could not escape, no detergent solution was used.

The Pherocon VI delta traps (Fig. 1d) also were from Trécé Incorporated. Each trap consisted of a sheet of white cardboard folded into a triangular tube with partially open ends. The sticky trapping surface was provided by an exchangeable card $\left(18.5 \mathrm{~cm}^{2}\right)$ that slid in and out swiftly and easily. The partial end closures could be opened flat for counting of the catch and for exchange of trapping cards. The trap was fitted with a wire linkage allowing it to be hung from a wooden post in the field.

Pheromone Lures Pheromone lures of rubber septa loaded with Z3-dodecenyl-E2-butenoate, sealed in an impermeable bag for shipping and storage, were obtained from Chem Tica Internacional S.A. (San José, Costa Rica). The lure packs, each containing $10 \mathrm{mg}$ of pheromone and emitting the active ingredient at $<0.01 \mathrm{mg} /$ day (Material Safety Data Sheet, ChemTica Internacional, S.A.), were stored at $4{ }^{\circ} \mathrm{C}$ until use. Lures were suspended on wires inside the ground traps, Pherocon unitraps, and funnel water traps. In the Pherocon delta traps, the lures were placed at the centers of the exchangeable sticky cards. Although $C$. formicarius pheromone can remain active in the field for 30-64 d (Jansson et al., 1992), our lures were changed at 30-d intervals, as recommended by Hwang (2000).

Effect of Trap Design The four trap types, with their pheromone lures, were placed at randomly chosen locations about $10 \mathrm{~m}$ apart in sweetpotato fields at the 4 test locations. Tests were replicated three times at each site to yield 12 replications. Traps without pheromone lures were used as controls. Overall, 96 traps were used: 8 treatments (4 trap designs, each with and without lures $) \times 3$ replications $\times 4$ sites. Each week, the trapped adult weevils were removed and counted and their numbers recorded. Traps were washed and rinsed, and new detergent solution added. We rotated trap positions weekly at each location to diminish positional effects on trap catch. The study was conducted from Feb-June 2010.

Effect of Trap Size In the second experiment, the effectiveness of four sizes of Pherocon unitraps $(20.5 \mathrm{~cm}$ height $\times$ $18 \mathrm{~cm}$ diam., $20.5 \times 13 \mathrm{~cm}, 17.5 \times 7.5 \mathrm{~cm}, 11 \times 9 \mathrm{~cm})$ was compared. At each site, three traps of each size were set up and their positions rotated weekly. Tests were replicated three times at each site to yield 12 replications. The study used 48 traps ( 4 trap sizes $\times 3$ replications $\times 4$ sites). The experiment was conducted from July-Oct. 2010.

Effect of Trap Color In the third experiment, 13-cm diam. Pherocon unitraps were covered entirely with brown, black, gray, yellow, red, white, green, or blue vinyl tape and tested independently ( 8 traps colors $\times 3$ replications $\times 4$ sites $)$ at the same sites. The experiment was carried out from Nov. 2010-Feb. 2011. Color characteristics of the tape were determined using a Konica Minolta CR-410 Chromometer (Minolta Instrument Systems, Ramsey, NJ, USA) and are given in Table 1.

Effect of Shade of Color In the fourth experiment, different shades of red (light red, tomato red, dark red, and candyapple red) were evaluated. The trap used was again the 13$\mathrm{cm}$ diam. Pherocon unitrap, and the shades were tested independently ( 4 shades of red $\times 3$ replications $\times 4$ sites) at the same sites. The experiment was conducted from Mar-June 2011. Different red trap-color measurement values are given in Table 2.

Effect of Trap Height In the fifth experiment, 60 (traps with 5 different heights $\times 3$ replications $\times 4$ sites) light red, $13-\mathrm{cm}-$ diam. Pherocon unitraps were placed at ground level and at $50,100,150$, and $200 \mathrm{~cm}$ above the crop canopy, $10 \mathrm{~m}$ apart. Trap height was adjusted according to crop growth in the field. Observations on trap catches were made at weekly intervals. The experiment was carried out from July-Sept. 2011.

Relative Effects of Visual and Olfactory Cues In the sixth experiment, light red, 13-cm-diam. Pherocon unitraps, placed $50 \mathrm{~cm}$ above the crop canopy, were baited with pheromone lures or left unbaited ( 1 trap with, and 1 without, lure $\times 3$ replications $\times 4$ sites $=24$ traps). The experiment was carried out at the same sites from Oct.-Dec. 2011.

Statistical Analysis Trap catch data were transformed by log $(x+1)$ to fit the assumption of homogeneity of variance for 
Table 1 Specifications of the colors of traps used

\begin{tabular}{|c|c|c|c|c|c|}
\hline Trap color & $\mathrm{L}^{*}$ & $a^{*}$ & $b^{*}$ & Chroma (C) & Hue angle $\left(\mathrm{h}^{\circ}\right)$ \\
\hline Black & $30.44 \pm 0.06$ & $0.42 \pm 0.03$ & $-1.08 \pm 0.04$ & $1.16 \pm 0.05$ & - \\
\hline Brown & $35.26 \pm 0.18$ & $3.98 \pm 0.03$ & $3.94 \pm 0.02$ & $5.60 \pm 0.03$ & $44.66 \pm 0.11$ \\
\hline Gray & $39.83 \pm 0.11$ & $-0.17 \pm 0.02$ & $-2.23 \pm 0.01$ & $2.24 \pm 0.01$ & $85.64 \pm 0.47$ \\
\hline Yellow & $82.57 \pm 0.02$ & $-2.92 \pm 0.03$ & $84.02 \pm 0.27$ & $84.07 \pm 0.27$ & $91.99 \pm 0.02$ \\
\hline Red & $42.84 \pm 0.11$ & $49.88 \pm 0.28$ & $19.44 \pm 0.20$ & $53.54 \pm 0.34$ & $21.29 \pm 0.09$ \\
\hline White & $92.29 \pm 0.03$ & $1.34 \pm 0.01$ & $-2.59 \pm 0.04$ & $2.91 \pm 0.03$ & - \\
\hline Green & $43.50 \pm 0.08$ & $-27.32 \pm 0.03$ & $1.72 \pm 0.09$ & $27.37 \pm 0.03$ & $176.39 \pm 0.19$ \\
\hline Blue & $36.02 \pm 0.10$ & $15.19 \pm 0.10$ & $-35.82 \pm 0.12$ & $38.91 \pm 0.14$ & $292.98 \pm 0.08$ \\
\hline
\end{tabular}

Means $( \pm$ SD) were generated from three observations

$L^{*}$ indicates a measure of "lightness" that runs through the center of the color chart; 100 at the top represents white, and zero at the bottom represents black

The a* axis, which runs left to right on the color chart, indicates a red shade when greater than zero (positive) and a green shade when lower than zero (negative). Similarly, the $b^{*}$ axis, which runs vertically through the color chart, indicates a yellow shade when positive and a blue shade when negative (Wrolstad et al., 2005)

Chroma is related to the saturation of a color, with lower chroma values being less saturated

The hue angle is expressed on a $360^{\circ}$ grid on which $0^{\circ}=$ red, $90^{\circ}=$ yellow, $180^{\circ}=$ green, and $270^{\circ}=$ blue

ANOVA. Because all responses used were count variables, a one-way Poisson ANOVA model was fitted, by means of the GLIMMIX Procedure SAS Version 9.3 (SAS Institute, 2009). The least square means test was used to make multiple comparisons for differences among treatments.

\section{Results}

Effect of Trap Design Traps of all the designs baited with pheromone lures captured C. formicarius but differed in numbers of adults caught: mean catches were in the order Pherocon unitrap $>$ funnel water trap $>$ ground trap $>$ Pherocon delta trap. Pherocon unitraps captured more adults than funnel water traps $(F=22.4 ; d f=7,21 ; P<0.05$; Fig. 2$)$, and ground traps more than Pherocon delta traps. Traps without lures (control) caught no adults. During the experimental period, the average temperature was $28.5{ }^{\circ} \mathrm{C}$, the average relative humidity $65-80 \%$, and the average wind velocity $5.8 \mathrm{~m} \cdot \mathrm{sec}^{-1}$. The Pherocon unitrap, which caught more adults than all the other traps, was selected for all further experiments.

Effect of Trap Size The smaller and larger traps were less effective than medium-sized traps. Pherocon unitraps of $13 \mathrm{~cm}$ diam. caught more $(F=8.6 ; d f=3,23 ; P<0.05$; Fig. 3) $C$. formicarius adults $(59.7 \pm 1.2$ adults/trap) than did the next larger size $(16.9 \pm 0.8$ adults/trap) and the two smallest size traps $(29.1 \pm 1.3$ and $32.0 \pm 1.6$ adults/trap, respectively); catches in the two smallest traps did not differ

Table 2 Specifications of the shades of red used on traps

\begin{tabular}{llllrr}
\hline Trap color & L* & $\mathrm{a}^{*}$ & $\mathrm{~b}^{*}$ & Chroma (C) & Hue angle $\left(\mathrm{h}^{\circ}\right)$ \\
\hline Candy-apple red & $43.13 \pm 0.06$ & $49.34 \pm 0.23$ & $19.53 \pm 0.28$ & $53.06 \pm 0.21$ & $21.59 \pm 0.31$ \\
Tomato red & $47.92 \pm 0.02$ & $43.82 \pm 0.06$ & $26.86 \pm 0.01$ & $51.40 \pm 0.06$ & $31.51 \pm 0.03$ \\
Light red & $50.03 \pm 0.06$ & $47.62 \pm 0.06$ & $28.79 \pm 0.08$ & $55.65 \pm 0.09$ & $31.16 \pm 0.04$ \\
Dark red & $42.76 \pm 0.06$ & $43.06 \pm 1.20$ & $19.67 \pm 0.02$ & $47.34 \pm 1.09$ & $24.56 \pm 0.61$ \\
\hline
\end{tabular}

Means $( \pm \mathrm{SD})$ were generated from three observations

$L^{*}$ indicates a measure of "lightness" that runs through the center of the color chart; 100 at the top represents white, and zero at the bottom represents black

The a* axis, which runs left to right on the color chart, indicates a red shade when greater than zero (positive) and a green shade when lower than zero (negative). Similarly, the $b^{*}$ axis, which runs vertically through the color chart, indicates a yellow shade when positive and a blue shade when negative (Wrolstad et al., 2005)

Chroma is related to the saturation of a color, with lower chroma values being less saturated.

The hue angle is expressed on a $360^{\circ}$ grid on which $0^{\circ}=$ red, $90^{\circ}=$ yellow, $180^{\circ}=$ green, and $270^{\circ}=$ blue 


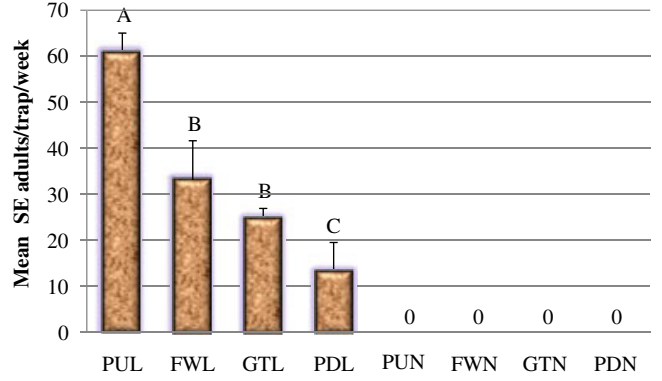

Fig. 2 Mean ( $\pm \mathrm{SE}$ ) numbers of adult Cylas formicarius caught by Pherocon unitrap with pheromone lure (PUL), funnel water trap with lure (FWL), ground trap with lure (GTL), Pherocon delta trap with lure (PDL), Pherocon unitrap without lure (PUN), funnel water trap without lure (FWN), ground trap without lure (GTN), and Pherocon delta trap without lure (PDN). Different capital letters indicate differences among treatments (two-way ANOVA with Poisson model, least square means, $P<0.005$ ). Means were generated from 12 replicates $(3$ replicates per location $\times 4$ sites)

from each other. Therefore, the $13 \mathrm{~cm}$ traps were used for all further experiments. During the experimental period, the average temperature was $30.2^{\circ} \mathrm{C}$, the average relative humidity $65-80 \%$, and the average wind velocity $5.2 \mathrm{~m} \cdot \mathrm{sec}^{-1}$.

Effect of Trap Color Red unitraps caught more adult $C$. formicarius than those of any other color tested $(F=11.31$, $d f=7, P<0.05$; Fig. 4), followed, in descending order, by grey, brown, blue, white, yellow, black and green traps; green traps caught fewer adults than any other. Therefore, red traps were used for all subsequent experiments. During the experimental periods, the average temperature was $27.8^{\circ} \mathrm{C}$, the average relative humidity $65-80 \%$, and average wind velocity was $4.4 \mathrm{~m} \cdot \mathrm{sec}^{-1}$.

Effect of Shade of Red Light-red unitraps caught more adults $(F=10.22, d f=3, P<0.05$; Fig. 5) than traps of other shades. Candy-apple red caught the fewest, whereas tomato

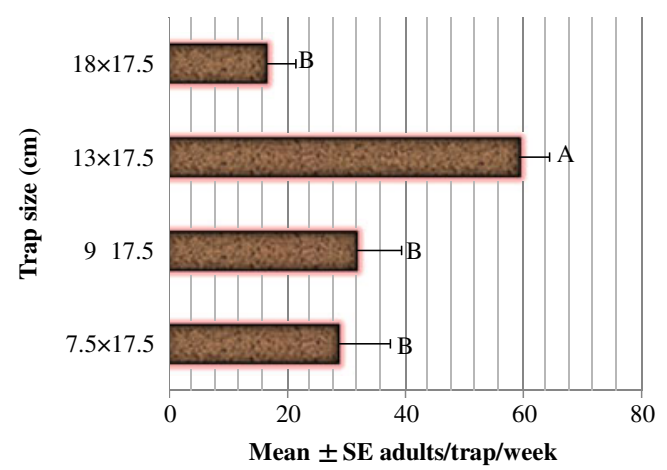

Fig. 3 Mean ( \pm SE) numbers of adult Cylas formicarius caught in pheromone-baited Pherocon unitraps of different size. Different capital letters indicate differences among treatments (one-way ANOVA with Poisson model, least square means, $P<0.05$ ). Bars represent means of 12 replicates ( 3 replicates per location $\times 4$ sites)

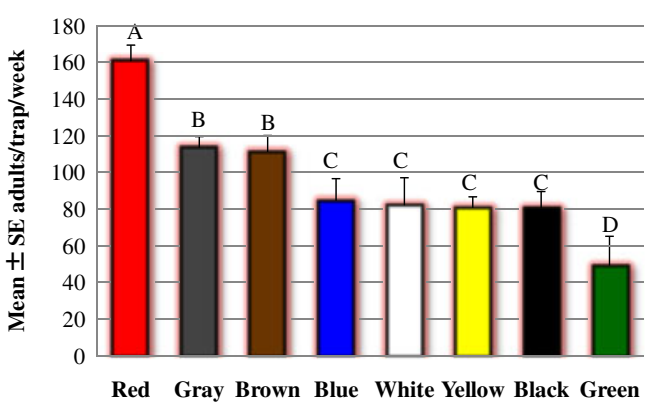

Fig. 4 Mean $( \pm \mathrm{SE})$ numbers of adult Cylas formicarius caught in pheromone-baited Pherocon unitraps of different color. Different capital letters indicate differences among treatments (one-way ANOVA with Poisson model, least square means, $P<0.01)$. Bars represent means of 12 replicates ( 3 replicates per location $\times 4$ sites)

red and dark red traps did not differ. Therefore, light-red traps were used for all subsequent experiments. During the experimental period, the average temperature was $29.4{ }^{\circ} \mathrm{C}$, the average relative humidity $65-80 \%$, and the average wind velocity $6.2 \mathrm{~m} \cdot \mathrm{s}^{-1}$.

Effect of Trap Height Traps installed $50 \mathrm{~cm}$ above the crop canopy caught more adults $(F=8.14, d f=4, P<0.01$; Fig. 6) than traps positioned on the ground or at other heights. Therefore, traps were positioned at $50 \mathrm{~cm}$ above the ground height for the remaining experiment. During the experimental periods, the average temperature was $27.3^{\circ} \mathrm{C}$, the average relative humidity $65-80 \%$, and the average wind velocity $4.4 \mathrm{~m} \cdot \mathrm{sec}^{-1}$.

Relative Effects of Visual and Olfactory Cues Light-red Pherocon Unitraps baited with pheromone lures caught more adults (mean of $1028.8 \pm 18.5$ ) than those without lures (mean of $22.0 \pm 8.8 ; F=13.22, d f=1, P<0.001$ ). During the experimental period, the average temperature was $30.5^{\circ} \mathrm{C}$, the average relative humidity $65-80 \%$, and the average wind velocity $7.8 \mathrm{~m} \cdot \mathrm{sec}^{-1}$.

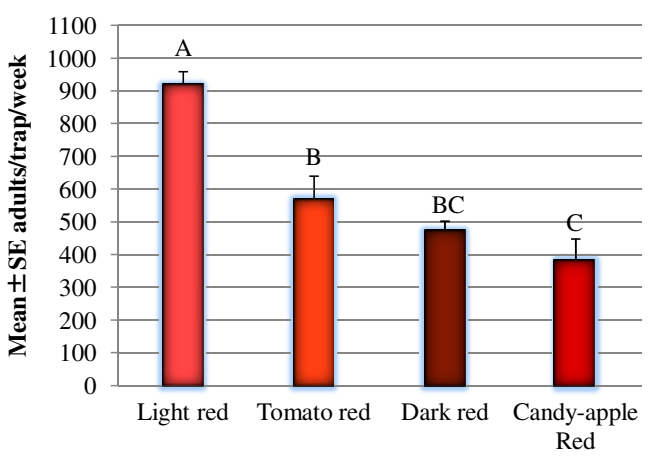

Fig. 5 Mean ( \pm SE) numbers of adult Cylas formicarius caught in pheromone-baited Pherocon unitraps of different shades of red. Different capital letters indicate differences among treatments (one-way ANOVA with Poisson model, least square means, $P<0.01$ ). Bars represent means of 12 replicates ( 3 replicates per location $\times 4$ sites) 


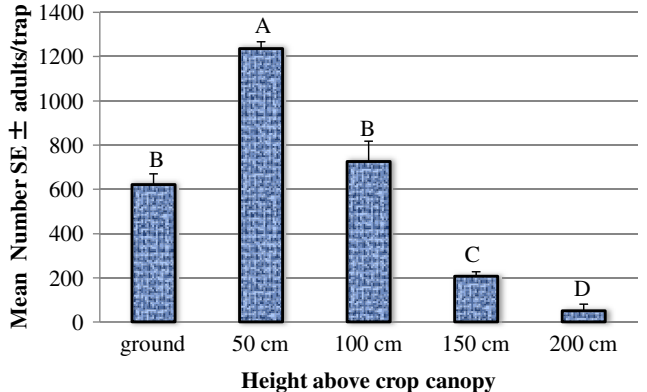

Fig. 6 Mean $( \pm \mathrm{SE})$ numbers of adult Cylas formicarius caught in light red unitraps mounted at different heights in a sweet-potato field. Different capital letters indicate differences among treatments (one-way ANOVA with Poisson model, least square means, $P<0.05$ ). Bars represent means of 12 replicates ( 3 replicates per location $\times 4$ sites)

\section{Discussion}

Nearly 10 years ago, Japanese scientists eradicated West Indian sweetpotato weevil, Euscepes postfasciatus (Fairmore) (Coleoptera: Curculionidae), from the Kume islands of Okinawa (Kuba et al., 2000) by means of the search and kill method. For C. formicarius, a similar approach should be considered. Because $C$. formicarius is more widespread in most sweetpotato growing areas than was E. postfasciatus, it will not be easy to eradicate. Pheromone-baited traps are useful for detecting the spread of $C$. formicarius and in alerting both growers and scientists to its presence, both in sweet-potato plants and in wild Ipomoea plants that harbor the weevil. Widespread indiscriminate destruction of Ipomoea spp. is not advisable, because these plants could be important to the local ecosystem, but infested plants around current or past sweetpotato plantings could be identified by means of pheromone-baited traps, and then uprooted, and burned.

Another approach, that of release of sterile males, is in use in the Okinawa islands for the control of $C$. formicarius and E. postfasciatus (Moriya, 1997), but this technique may have limited value because, unlike melon fly, Bactrocera cucurbitae (Coquillett) (Diptera: Tephritidae) (Koyama et al., 2004), C. formicarius adults are not especially active fliers. Like other members of the family Brentidae, C. formicarius adults crawl from place to place (Chalfant et al., 1990), limiting the extent to which sterile males might mate with normal females. While $C$. formicarius is not a strong flier, it readily mates when on foliage, and this is what is targeted with the male sterilization approach. In addition to C. formicarius, other Coleoptera also have been treated in sterile insect technique (SIT) programs, such as the cockchafer, Melolontha vulgaris L. (Scarabaeidae), and the boll weevil, Anthonomus grandis Boheman (Curculionidae), with remarkable results (Dyck et al., 2005). Nevertheless, an efficient pheromone-trapping technique is required for $C$. formicarius, either to use in conjunction with SIT programs, or for management or eradication.

According to Jackson and Bohac (2006), although current trap designs are effective for monitoring $C$. formicarius, they are cumbersome, difficult to sustain, or costly. Those authors suggested that more work is needed to develop simple, inexpensive, and effective traps for monitoring $C$. formicarius. Our results showing that Pherocon unitraps were more effective than other types for $C$. formicarius apparently contrast with the study of Smit et al. (1997), who reported that Unitraps performed relatively poorly for the congeneric C. puncticollis (Boheman) and C. brunneus F. (Coleoptera: Curculionidae). They also reported that Unitraps were commercially available, but were too expensive for routine use in Uganda. Although, the trap design we used was identical to that in their study, the different relative trap efficiencies may be due to differences in behavior between the African sweetpotato weevils they studied and $C$. formicarius.

Of the 10 trap designs evaluated by Jackson and Bohac (2006), a funnel trap (a modification of a water-pan trap) and the Pherocon sticky trap were the most effective for capturing adults. The better performance of the unitraps, compared to the generic water funnel trap in our study, may have been due to the continuous rainfall received by our study areas. Simple water-pan traps often are used in developing countries (Pillai et al., 1993), but we found them to be the least effective.

In our study, the medium-sized (13-cm diam.) trap outperformed both larger and smaller traps. The importance of trap size for other weevil species has been highlighted in a previous study (Reddy et al., 2011). Trap-catch differences for Arhopalus rusticus nubilus (Le-Conte) (Coleoptera: Cerambycidae) and Xyleborus spp. between 8- and 16-unit traps may be related to differences in trap surface area for interception of beetles, or to preference for taller vertical silhouettes (Hoover et al., 2000). In contrast, catches of the reproduction weevil, Hylobius pales Herbst (Curculionidae), in 16-unit traps were $54 \%$ lower than those in 8-unit traps (Miller and Crowe, 2009).

The study reported here is the first to demonstrate a color preference by $C$. formicarius, although the importance of color preference by nocturnal insects and other curculionid weevils has been demonstrated previously (Reddy et al., 2011). Abdallah and Al-Khatri (2005) reported that more adult Rhynchophorus ferrugineus Olivier (Coleoptera: Curculionidae) were attracted to red and orange, than to blue, traps. Our findings differ from those of Smit et al. (1997), who observed that trap color was not critical for $C$. puncticollis and C. brunneus, although red traps had lower catches than yellow and white traps, which were the predominant colors available in Uganda. 
In our study, traps installed $50 \mathrm{~cm}$ above the crop canopy had higher catches than those at other heights. These results differ from those of Yasuda et al. (1992), who reported that sticky traps, at the same height as the crop canopy, caught more $C$. formicarius than traps at heights up to $300 \mathrm{~cm}$. Because nocturnal weevils habitually crawl to the topmost leaves of sweetpotato plants (Proshold et al., 1986), pheromone traps surrounded by sweetpotato foliage should capture more insects than traps that are not surrounded (Jansson et al., 1992). Trap height is known to influence capture of other weevil pests. For example, Faleiro (2006) reported the greatest $R$. ferrugineus catches at $1.0 \mathrm{~m}$ above the ground. Smit et al. (1997) noted that raising the trap until the entrance holes were 15 or $30 \mathrm{~cm}$ above the canopy improved catches of $C$. puncticollis, whereas catches of C. brunneus were unaffected by trap height. Our results on trap height effectiveness contrast with those on C. formicarius by Proshold et al. (1986), who reported that raising the trap above crop height critically reduced adult catches.

Visual cues alone influence the behavior or catches of weevil populations (Reddy and Raman, 2011). In the present study, we found that light red traps caught more $C$. formicarius than other traps. We suggest that trap color could be important because the flight activity of $C$. formicarius may occur during crepuscular times. Björklund et al. (2005) reported that traps baited solely with odor or solely with visual stimuli catch more pine weevils, Hylobius abietis (L.) (Coleoptera: Curculionidae), than stimulus-free traps. Odor and visual stimuli also have been shown to have additive effects on trap catch (Reddy, 2012), and traps with a combination of odor and visual stimuli catch more weevils than traps with odor or visual stimuli alone (Björklund et al., 2005). In the current study, traps baited with pheromone captured more $C$. formicarius than did identical traps without pheromone. This result is in agreement with previous observations on several other weevils that use olfactory (pheromones), rather than visual, cues (see Reddy et al., 2011, and references therein), although Tansey et al. (2010) reported that the cabbage seedpod weevil, Ceutorhynchus obstrictus (Marsham) (Coleoptera: Curculionidae) also is influenced by visual cues. Reeves (2011) described the importance and use of vision for locating host plants, with some recent examples showing that vision can be even more important than olfaction.

We conclude that trap design, size, color, and height affect the response of $C$. formicarius to pheromone-baited traps. In particular, the $17.5 \times 13-\mathrm{cm}$, light-red Pherocon unitraps baited with pheromone lures and installed $50 \mathrm{~cm}$ above the crop canopy gave the highest catches of $C$. formicarius. These results are useful and should be taken into consideration when trap-and-kill strategies are developed.
Acknowledgements This project was supported by FY 2011 Pacific Islands Area Conservation Innovation Grants (PIA-CIG) Program, Grant Agreement No. 69-9251-11-902, The Natural Resources Conservation Service (NRCS)-USDA; Western Integrated Pest Management Center (WIPMC) Award \# 2007-51120-03885/ University of California, Davis sub-award \# 07 -001492-GUAM3, and USDA Hatch funds (Project\# GUA0561). In accordance with federal law and USDA policy, this institution is prohibited from discrimination on the basis of race, color, national origin, sex, age, or disability. We also thank R. Gumataotao, G. McNassar, and J. Remolona for help during field work. Part of the work was made possible from two Summer Apprenticeship Programs for Nirupa Gadi and A.J. Taianao at the University of Guam.

\section{References}

AbDallah, F. F. and Al-Khatri, S. A. 2005. The effect of pheromone, kairomone and food bait on attracting adults of red palm weevil Rhynchophorus ferrugineus in the Sultanate of Oman in date palm plantations. Egyptian J Agric Res. 83:69-177.

Austin, D. F., Jansson, R. K., and Wolfe, G. W. 1991. Convolvulaceae and Cylas: a proposed hypothesis on the origins of this plant/insect relationship. Trop Agric. 68:162-170.

BJÖRKLUND, N., NORDLandER, G., and BYLUND, H. 2005. Olfactory and visual stimuli used in orientation to conifer seedlings by the pine weevil, Hylobius abietis. Physiol Entomol. 30:225-231.

BRAUn, A. R. and VAN DE FLIERT, E. 1999. Evaluation of the impact of sweetpotato weevil (Cylas formicarius) and the effectiveness of Cylas sex pheromone traps at the farm level in Indonesia. Int $J$ Pest Manage. 45:101-110.

Chalfant, R. B., Jansson, R. K., Seal, D. R., and Schalk, J. M. 1990. Ecology and management of sweet potato insects. Annu Rev Entomol. 35:157-180.

Coffelt, J. A., Vick, K. W., Sower, L. L., and McClellan, W. T. 1978. Sex pheromone of the sweetpotato weevil, Cylas formicarius elagantulus: Laboratory bioassay and evidence for a multiple component system. Environ Entomol. 7:756-758.

Downham, M. C. A., Smit, N. E. J. M., Laboke, P. O., Hall, D. R., and ODONGO, B. 2001. Reduction of pre-harvest infestations of African sweetpotato weevils Cylas brunneus and C. puncticollis (Coleoptera: Apionidae) using a pheromone mating-disruption technique. Crop Prot 20:163-166.

Dyck, V. A., Hendrichs, J., and Robinson, A. S. (EDS.) 2005. pp. 787 , Sterile insect technique. Principles and practice in area-wide integrated pest management. Springer, Dordrecht, Netherlands.

FALEIRO, J. R. 2006. Insight into the management of red palm weevil Rhyncophorus ferrugineus Olivier: based on experiences on coconut in India and date palm in Saudi Arabia, pp. 35-57, in F. Agroalimed (ed.), I Jornada Internacional sobre el Picudo Rojo de las Palmeras (November, 2005). Fundación Agroalimed, Valencia, Spain.

Heath, R. R., Coffelt, J. A., Sonnet, P. E., Proshold, F. I., Dueben, B., and TumLinson, J. H. 1986. Identification of sex-pheromone produced by female sweetpotato weevil, Cylas formicarius elegantulus (Summers). J Chem Ecol. 12:1489-1503.

Hoover, S. E. R., Lindgren, B. S., KeEling, C. I., and Slessor, K. N. 2000. Enantiomer preference of Trypodendron lineatum and effect of pheromone dose and trap length on response to lineatinbaited traps in interior British Columbia. J Chem Ecol. 26:667677.

JACKSON, D. M. and BOHAC, J. R. 2006. Evaluation of pheromone traps for monitoring sweetpotato weevils. J Agric Urban Entomol. 23:141-158. 
Jansson, R. K., Bryan, H. H., and SORENSEN, K. A. 1987. Withinvine distribution and damage of sweet potato weevil, Cylas formicarius elegantulus (Coleoptera: Curculionidae), on four cultivars of sweet potato in southern Florida. Florida Entomol. 70:523-526.

Jansson, R. K., Mason, L. J., Heath, R. R., Sorensen, K. A., HAMMOND, A. M., and RoBInson, J. V. 1992. Pheromone-trap monitoring system for sweetpotato weevil (Coleoptera: Apionidae) in the southern United States: effects of trap type and pheromone dose. J Econ Entomol. 85:416-423.

Jansson, R. K., Mason, L. J., Heath, R. R., LeCrone, S. H., and FOREY, D. E. 1993. Pheromone-trap monitoring system for sweetpotato weevil (Coleoptera: Apionidae) in the southern United States: effects of lure type, age and duration in storage. $J$ Econ Entomol. 86:1109-1115.

KOYAMA, J., KAKINOHANA, H., and MiYATAKE, T. 2004. Eradication of the melon fly, Bactrocera cucurbitae, in Japan: importance of behavior, ecology, genetics, and evolution. Annu Rev Entomol. 49:331-349.

Kuba, H., Teruya, T., and SaKakibara, M. 2000. Eradication of weevils by sterile-insect-release methods (9): experimental eradication project of sweet potato weevils in Kume Island [in Japanese]. Plant Prot. 54:483-486.

Miller, D. N. and CROWE, C. M. 2009. Length of multiple-funnel traps affects catches of some bark and wood boring beetles in a slash pine stand in northern Florida. Florida Entomol. 92:506-507.

MoRIYA, S. 1997. Is it possible to eradicate the two weevil pests of sweet potato, Cylas formicarius and Euscepes postfasciatus from Japan? Bull Okinawa Agric Exp Stn. 18:19-27.

Alcázar, J., Cisneros, F., and Morales, A. 1997. Large-scale implementation of IPM for sweetpotato weevil in Cuba: a collaborative effort, pp. 185-190, in Program Report 1995-1996, International Potato Center, Lima, Peru.

Hwang, J. S. 2000. Integrated control of sweetpotato weevil, Cylas formicarius Fabricius, with sex pheromone and insecticide, pp 25-43, in C. Chien (ed.). Sweet Potato Production. Tsukuba, Ibaraki, Japan.

HwANG, J. S. 2001. Integrated control of sweetpotato weevil, Cylas formicarius Fabricius, with sex pheromone and insecticide. Extension Bulletin-Food \& Fertilizer Technology Center, Taipei: Food and Fertilizer Technology Center for the Asian and Pacific Region.

Pillai, K. S., Rajamma, P., and Palaniswami, M. S. 1993. New technique in the control of sweet potato weevil using synthetic sex pheromone in India. Int J Pest Manage. 39:84-89.

Proshold, F. I., Gonzalez, J. L., Asencio, C., and Heath, R. R. 1986. A trap for monitoring the sweetpotato weevil (Coleoptera: Curculionidae) using pheromone or live females as bait. $J$ Econ Entomol. 79:641-647.

REDDY, G. V. P. 2012. Recent trends in the olfactory responses of insect natural enemies to plant volatiles, pp. 281-301, in G. Witzany and F. Baluska (eds.), Biocommunication of Plants. Springer, Heidelberg, Germany.

REDDY, G. V. P. and Guerrero, A. 2004. Interactions of insect pheromones and plant semiochemicals. Trends Plant Sci. 9:253-261.
RedDy, G. V. P. and GuERrero, A. 2010. New pheromones and insect control strategies. Vitam Horm. 83:493-519.

REDDY, G. V. P. and RAMAN, A. 2011. Visual cues are relevant in behavioral control measures for Cosmopolites sordidus (Coleoptera: Curculionidae). J Econ Entomol. 104:436-442.

Reddy, G. V. P., FetTKöther, R., Noldt, U., and DettNer, K. 2005. Capture of female Hylotrupes bajulus as influenced by trap type and pheromone blend. J Chem Ecol. 31:2169-2177.

RedDy, G. V. P., Balakrishnan, S., Remolona, J. E., KiKuchi, R., and BAMBA, J. P. 2011. Influence of trap type, size, color, and trapping location on the capture of the New Guinea sugarcane weevil, Rhabdoscelus obscurus (Coleoptera: Curculionidae). Ann Entomol Soc Am 104:594-603.

REEVES, J. L. 2011. Vision should not be overlooked as an important sensory modality for finding host plants. Environ Entomol. 40:855-863.

SAS InSTITUTE, INC 2009. SAS/STAT user's guide, release 9.3. SAS Institute, Cary, NC.

Smit, N. E. J. M., Downham, M. C. A., Odongo, B., Hall, D. R., and LABOKE, P. O. 1997. Development of pheromone traps for control and monitoring of sweetpotato weevils, Cylas puncticollis and C. brunneus, in Uganda. Entomol Exp Appl. 85:95-104.

StRONG, L. A. 1983. Report of the Chief of the Bureau of Entomology and Plant Quarantine. United States Department of Agriculture, Washington.

Sureda, T., Quero, C., Bosch, M. P., Aviles, R., Coll, F., Renou, M., and GUERRERO, A. 2006. Electrophysiological and behavioral responses of a Cuban population of the sweet potato weevil to its sex pheromone. J Chem Ecol. 32:2177-2190.

SuTHERLand, J. A. 1986. A review of the biology and control of the sweetpotato weevil Cylas formicarius (Fab). Trop Pest Manage. 32:304-315.

TALEKAR, N. S. 1983. Infestation of a sweetpotato weevil (Coleoptera: Curculionidae) as influenced by pest management techniques. $J$ Econ Entomol. 76:342-344.

Tansey, J. A., Dosdall, L. M., Keddie, B. A., and Noble, S. D. 2010. Contributions of visual cues to cabbage seedpod weevil, Ceutorhynchus obstrictus (Marsham) (Coleoptera: Curculionidae), resistance in novel host genotypes. Crop Prot. 29:476-481.

Uritani, I., SAITO, T., HoNDA, H., and KIM, W. K. 1975. Introduction of furano-terpenoids in sweet potato roots by the larval components of the sweet potato weevils. Agric Biol Chem. 37:18571862.

Woolfe, J. A. 1992. pp. 643, Sweetpotato: An Untapped Food Resource. Cambridge University Press, Cambridge, England.

Wrolstad, R. E., Durst, R. W., and LeE, J. 2005. Tracking color and pigment changes in anthocyanin products. Trends Food Sci Tech. $16: 423-428$.

YASUDA, K. 1995. Mass trapping of the sweetpotato weevil Cylas formicarius (Fabricius) (Coleoptera: Brentidae) with a synthetic sex pheromone. Appl Entomol Zool. 30:31-36.

YAsudA, K., Sugie, H., and Heath, R. R. 1992. Field evaluation of synthetic sex-attractant pheromone of the sweet-potato weevil, Cylas formicarius Fabricius (Coleoptera: Brentidae). Japan J Appl Entomol Zool. 36:81-87. 